\title{
A IMPORTÂNCIA DO GEORREFERENCIAMENTO: DESAFIOS E POSSIBILIDADES
}

\author{
Eduardo Pautz ${ }^{1}$
}

\begin{abstract}
RESUMO: O georreferenciamento está cada vez mais presente no atual cenário brasileiro, e tem demonstrado mais eficácia a partir de seus desafios e possibilidades. O objetivo desse artigo foi discorrer sobre a contribuição e importância do georreferenciamento no cenário de imóveis rurais. A metodologia utilizada foi a revisão bibliográfica para conceituar e buscar ideias que fossem pertinentes ao desenvolvimento desse trabalho. Concluiu-se que o georreferenciamento além de ser eficaz na localização, mapeamento e fiscalização exigido pelo INCRA tem atuado diretamente com sistemas que vem inovando e contribuindo com uma tecnologia bem mais rápida para desempenhar os registros de imóveis com mais segurança e confiabilidade, esta viabilidade além de ser agora obrigatória pela mudança das leis tem demonstrado as possibilidades e os desafios delineando novos estudos para a área que vem se destacando no cenário mercadológico.
\end{abstract}

Palavras-chave: Desafios. Georreferenciamento. INCRA. Inovação com Tecnologias.

\section{INTRODUÇÃO}

A importância do presente estudo teve como linha de pesquisa discorrer sobre o georreferenciamento em conceitos e as mudanças que foram surgindo com a legislação que trouxeram para este atual panorama as principais tendências desse instrumento que tem se destacado com muita evidência sobre os imóveis rurais.

Historicamente a apropriação de terras vista no cenário desde a idade remota da civilização vinha de grandes conquistas, de instrumentos que possibilitassem a transição e

\footnotetext{
I Graduação em Gestão Ambiental pela Universidade Metropolitana de Santos (2015). Especialista em Geoprocessamento e Georreferenciamento pela Faculdade Única de Ipatinga, Técnico em Agropecuária/Agrimensura pelo IFES e graduando em Agronomia pela UNEC, tem experiência na área de Desenvolvimento Sustentável, Consultoria Agrícola, Ambiental, Topografia, Georreferenciamento e Agrimensura.
} 
observação de terras distantes e a conquista de grandes civilizações pelo mundo (PALHARES, 2009).

Em outras considerações de dados levantados pela literatura, os apontamentos mostram que antes de georreferenciar vários instrumentos surgiram na terra para prover adequação a localização, mapeamento e fiscalização das terras como na própria demarcação.

Segundo Folles (2008) antes do surgimento de técnicas que pudessem ser utilizadas pelo homem, em períodos históricos esse indivíduo já fazia uso das terras em sua produção natural usando tudo que pudesse retirar do meio ambiente, essas condições eram desenvolvidas por civilizações muito avançadas com relação às terras como os Egípcios, Gregos e Romanos que foram determinantes sob o estudo da divisão de terras e suas demarcações.

O presente trabalho tem como objetivo foi discorrer sobre a contribuição e importância do georreferenciamento no cenário de imóveis rurais.

"Com o advento da referida lei, foi estabelecido um novo preceito na identificação dos imóveis rurais, com base na medição do imóvel com suporte geodésico." (FOLLE, 2008, p.23).

Em outras palavras, a conceituação de Georreferenciamento é:

O georreferenciamento consiste na descrição do imóvel rural em suas características, limites e confrontações, realizando o levantamento das coordenadas dos vértices definidores dos imóveis rurais, georreferenciados ao sistema geodésico brasileiro, com precisão posicional fixada pelo INCRA (BRASIL, 200I, p.o8).

Contudo ao buscar na literatura as principais ideias, encontrou-se como questionamento o seguinte problema: $O$ georrefereciamento tem contribuído para a fiscalização dos imóveis rurais com confiabilidade no atual cenário?

E para responder a tal questionamento utilizou a revisão bibliográfica para conceituar e buscar ideias que fossem pertinentes ao desenvolvimento desse trabalho.

Em alguns apontamentos da literatura percebe-se que os homens usavam vários instrumentos para fazer a localização de terras como, bússolas, mapas, leituras nas quais podiam se referenciar para atender as suas metas de conquistas. 
No entanto, historicamente milhares de anos passaram e novos instrumentos criados pelo homem foram substituindo os mais antigos trazendo a eficácia da modernidade.

Oliveira (2017, p.or) salienta que "Encontrar o fiel entre a mais exata e perfeita demarcação e a organização técnica e administrativa cartorial é o que se visualiza no cenário brasileiro do georreferenciamento e da certificação atual."

Nesse sentido, com as mudanças constantes no cenário brasileiros, as tendências da eficácia sobre os imóveis foram sendo modificados por novas tecnologias importantes e dentre elas o surgimento do georreferenciamento tem adequado com equilíbrio as novas formas de demarcação de terras dos seus proprietários com mais confiabilidade.

Portanto, o interesse pelo tema se justifica devido ao tema ser inovador deixando obvio que as tendências têm elevado a sua implementação e as novas mudanças na Legislação que fazem o georreferenciamento uma das melhores técnicas em todos os aspectos para os imóveis rurais emitirem seus certificados com segurança e confiabilidade, de forma que as tecnologias têm melhorado gradativamente os desafios e possibilidades da contribuição direta do georreferenciamento no cenário atual.

\section{DESENVOLVIMENTO}

Com o atual cenário em pleno desenvolvimento, as inovações de sistemas mais avançados foram sendo trazidas para a sociedade contribuindo com várias áreas em estudo, e no sistema de medição de terras está tendência foi sendo conduzida através da criatividade do homem com a criação de instrumentos importantes como os mapas, as bússolas e o próprio sistema de navegação como o GPS, e o surgimento desses instrumentos trouxeram novas possibilidades ao cenário do imóvel rural como o georreferenciamento.

Segundo Costa (2018), Júnior (2010) os primeiros instrumentos para localização e demarcação de terras eram realizadas através de instrumentos como mapas, bússolas e outros como o GPS após chegar a contemporaneidade, e podem ser vistas abaixo como exemplos de figuras. 
Figura I - Bússola

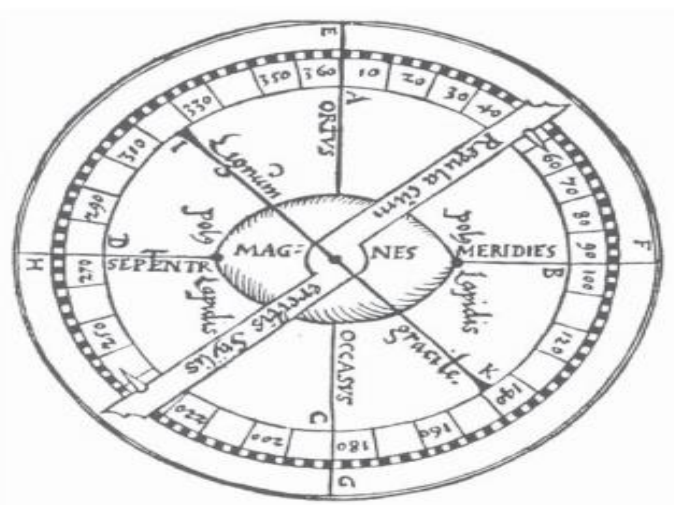

Fonte: Júnior (2010, p.208) Bússola flutuante feita de pedra-imã, usada para encontrar o azimute de qualquer corpo celeste no horizonte, proposta por Peregrinus em i269 (HARRADON, i943a, p. I4).

Segundo Oliveira (2018, p.08): “A bússola pode ser um dos instrumentos mais antigos utilizados na civilização desde os primórdios, nos quais seu contexto histórico teve como referencial as pedras ímãs, que eram referenciadas ao magnetismo.”

Outro instrumento muito antigo utilizado no mundo são os mapas que coincidentemente ainda são usados e atribuídos à conduta educacional para os conhecimentos de continentes, regiões, Américas e outros como descrito abaixo na figura:

Figura 2 - Exemplo de Mapas

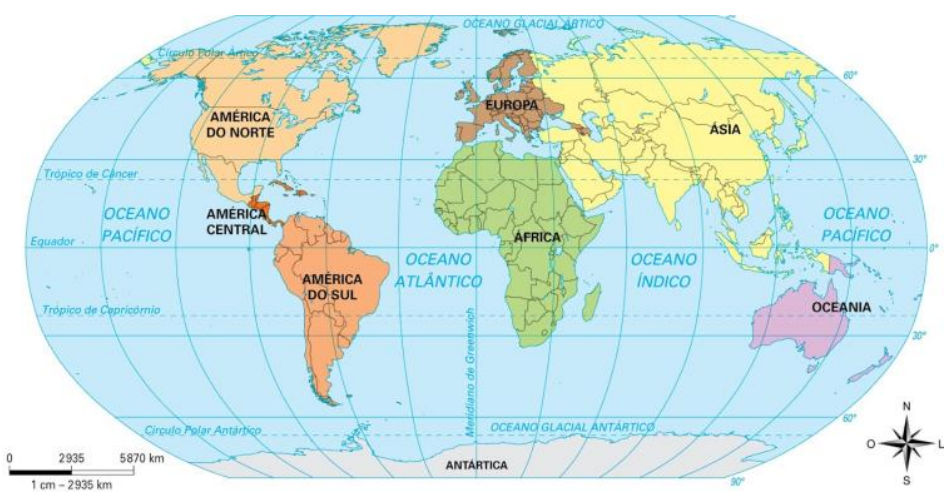

Fonte: Júnior (2010)

Enfim, com a chegada das tecnologias o uso tanto dos mapas quanto das bússolas foi modificando o cenário através da inovação tecnológica que surgiu num período massificado e globalizado pelas novas tendências que acertaram com os sistemas mais avançados, GPS e a chegada do georreferenciamento para imóveis rurais. 
Assim os primeiros conceitos sobre o georreferenciamento estão cada vez mais presentes pela sua importância atual e pela melhoria nos sistemas de fiscalização que permite a confiabilidade de registrar o imóvel rural e certificar para os seus proprietários com segurança.

Em outras palavras,

O georreferenciamento foi instituído em nosso sistema jurídico via alteração dos art. 176 e 225 da Lei dos Registros Públicos (n. 6.015/73), por força da lei n. 10.267/200I. Por esses dispositivos, o proprietário rural, em prazos que a norma regulamentadora viria instituir, deveria promovê-la, mediante utilização do sistema geodésico brasileiro e às suas expensas, em casos de desmembramento, parcelamento e remembramento e, obrigatoriamente, em caso de alienação do imóvel rural, pena de ver gessado o direito de fruição de seu imóvel. Tais dispositivos foram regulamentados pelo Dec. 4.449/2002, que pormenorizou os deveres do proprietário. $O$ georreferenciamento de acordo com essa legislação tem duas funções básicas: a de servir de instrumento de Registro Público, possibilitando a segurança no tráfico jurídico de imóveis; e a de servir de instrumento de cadastro, com a finalidade preponderantemente fiscalizatória, como, aliás, dispõe o art. IO. e seus parágrafos da Lei n. 5.868/72, que trata do cadastramento rural, alterado também pela dita lei n. 10.267/or. (grifamos) (OLIVEIRA JÚNIOR, 2005, p.7o).

Durante muito tempo Costa (2018) e Viana (2007) salientaram que as falhas

ocorridas dentro de cartórios e a falta de confiabilidade sob os registros e demarcação trouxeram muitos impactos na sociedade civil, nos quais as falhas ao fazer a demarcação pelos Engenheiros e responsáveis do INCRA acabavam tendo atribuições demoradas para averiguação das terras, possíveis problemas com fraudes na fiscalização e demarcação foram os maiores impasses ocorridos, e após a implantação do georreferenciamento com sistemas que pudessem fazer de forma mais rápida e correta o trabalho, tais problemática foram minimizadas pelas possibilidades desse instrumento ser mais eficaz e ligeiro obtendo dados catalogados com mais precisão.

Contudo, é preciso fazer uma menção de suas principais conceituações como discorre Costa (2018, p.oI):

O Georreferenciamento é uma ferramenta que permite determinar a posição exata de um imóvel e a sua área. Nesse mapeamento, estão disponíveis as coordenadas geográficas de posição de todas as suas confrontações, permitindo ao proprietário saber exatamente onde começam e onde terminam as suas terras. Georreferenciar o imóvel é definir a sua forma, dimensão e localização, tudo por meio de levantamento topográfico. O memorial descritivo deve ser realizado por um profissional habilitado - com a emissão da devida Anotação de 
Responsabilidade Técnica (ART), contendo as coordenadas dos vértices definidores dos limites dos imóveis rurais.

O interesse conceitual do georreferenciamento explicações jurídicas Folle (2008, p.25) que "o georreferenciamento é uma técnica moderna de agrimensura." No entanto na visão de Roque (2006, p.87) "A determinação precisa de um ponto na superfície terrestre dá-se o nome de georreferenciamento.”

E ainda na percepção de Folle (2008, p.27) o georreferenciamento é atribuído assim:

Quem executa o georreferenciamento são profissionais inscritos nos Conselhos Regionais de Engenharia e Arquitetura (CREA) habilitados no INCRA, que, através da Anotação de Responsabilidade Técnica (ART), assumem a responsabilidade pelos serviços. Esses profissionais, ao assumirem tal responsabilidade, ficam obrigados a responder por danos que a má execução de seus trabalhos possa ocasionar.

Deste modo, os apontamentos da literatura mostram que o georreferenciamento tanto na sua concepção definida como na abordagem de sistemas avançados que favorecem diretamente um ponto de referência, sua localização, e modernidade na técnica são atribuídas e conduzidas de acordo com a Lei no. I0.267/or em que são realizadas a fiscalização, demarcação, localização e medição que permitem o imóvel ser registrado e certificado com segurança e confiabilidade.

No entanto um exemplo claro de georreferenciamento pode ser visto abaixo na figura

Figura 3 - Georreferenciamento

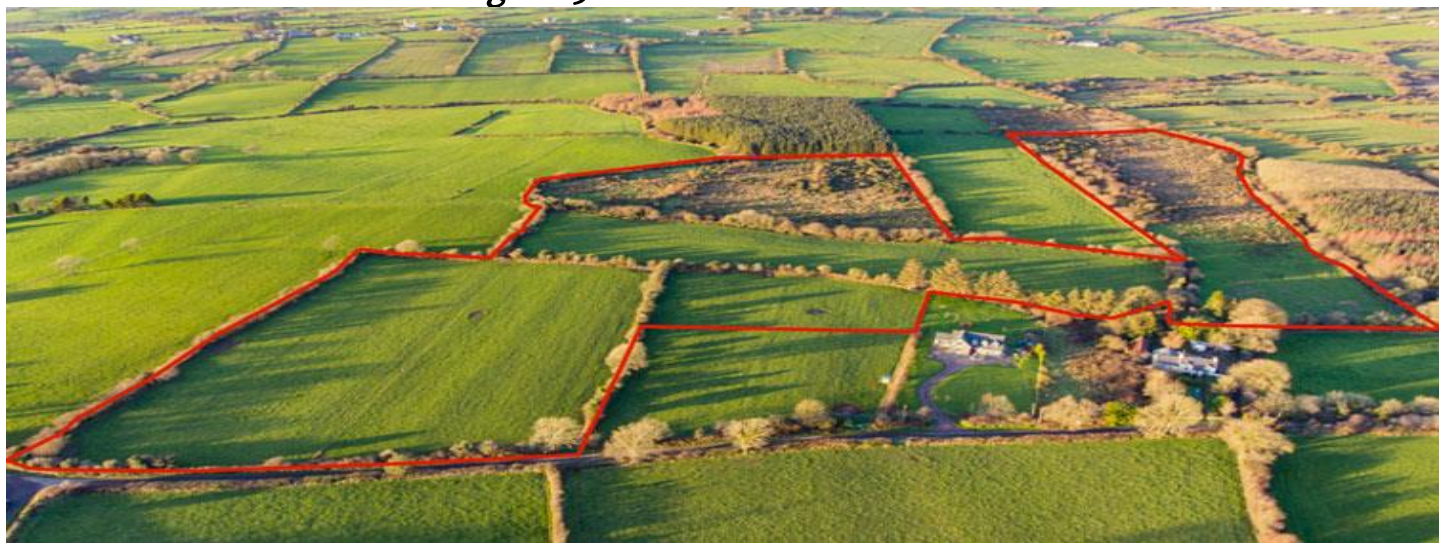

Fonte: Costa (2018)

Nesse sentido, a importância do georrefenciamento tem contribuído diretamente com os tipos de registros e certificações que o INCRA exige dos proprietários de imóveis 
rurais, visto que o governo federal quer acabar com qualquer tipo de fraude e falha sob as terras que não são demarcadas, assim possibilitando a sua gestão conferir as terras que são da vigência e estão sob os devidos poderes públicos.

Em outras palavras, o INCRA Instituto Nacional da Reforma Agrária tem como finalidade fazer à prestação de serviços de acordo com sua atribuição e função no qual lhe compete à elaboração de registro de cadastro público, seguindo todas as vigências outorgadas na Lei de no. I0.267/or, conforme prescrita (COSTA, 2018; INCRA. 2014, ALVES, SOUZA, LANA, 2017).

Nesse sentido, o georreferenciamento atualmente tem sido visto como um dos processos que tem demonstrado segurança e confiabilidade no suporte principal dos registros de imóveis rurais bem como atender as vigências em lei que tendem a novas mudanças que o INCRA tem realizado com mais equidade nos parâmetros e diretrizes legais.

\section{CONCLUSÃO}

A realização do trabalho procurou-se fazer uma abordagem direta das primeiras concepções sobre os tipos de instrumentos encontrados no cenário mundial que desse um álibi ao georreferenciamento.

Estudos na literatura apontaram que antes a modernidade das tecnologias com o GPS e o Georreferenciamento, a atenção e preocupação do homem no período da Antiguidade ainda era retirar das terras os seus proventos, e usar o máximo possível do meio natural, contudo os esgotamentos desses recursos fizeram com que o homem primitivo fosse deslocando de um lugar para outro, e assim sequencialmente com o passar dos séculos, as grandes civilizações em suas conquistas nas guerras também foram deslocando-se a conquistar novos ares, usando assim instrumentos como mapas e as bússolas para encontrar terras férteis, que lhes dessem vantagens, sobrevivência e poder.

Ainda assim os usos dos instrumentos também eram para localizar, demarcar lugares e terras distantes, nos quais permitiam aos grandes reis uma autarquia como donos das terras. 
No entanto, com os milhares de anos passados, $e$ as novas tendências da modernidade evidenciada pela evolução da Internet e de novos recursos e sistemas, a demarcação de terras, localização e certificação para registros de imóveis rurais ganharam novas ferramentas que gradativamente foram melhorando as possibilidades de outras técnicas que compuseram este cenário dos imóveis rurais.

Com a chegada do georreferenciamento a melhoria das técnicas na prestação de serviços atendeu ao objetivo desse trabalho bem como respondeu ao questionamento e interesse na temática desse estudo, sugerindo a continuidade de outros estudos que possam contribuir para melhorar os conhecimentos sobre o georreferenciamento.

Concluiu-se que o georreferenciamento além de ser eficaz na localização, mapeamento e fiscalização exigido pelo INCRA tem atuado diretamente com sistemas que vem inovando e contribuindo com uma tecnologia bem mais rápida para desempenhar os registros de imóveis com mais segurança e confiabilidade, esta viabilidade além de ser agora obrigatória pela mudança das leis tem demonstrado as possibilidades e os desafios delineando novos estudos para a área que vem se destacando no cenário mercadológico.

\section{REFERÊNCIAS}

ALVES, Marcos Morais; SOUZA, Alcione Wagner de; LANA, Fabiana de Araújo. Georreferenciamento: regularização de imóveis rurais. Jornal de Engenharia, tecnologia e meio ambiente, № 2. Vol. I 2017/I. Disponível em: $<$ publicacoes.facthus.edu.br/index.php/geral/article/download/.../Georeferenciament o>. Acesso em: 2I Set. 2018.

BRASIL, Tiago Malheiros. Retificação de imóvel rural e a obrigatoriedade do georreferenciamento de acordo com a lei 10.267 de 20oI. Curso de Direito da Universidade Salvador, 2013. Disponível em: $<$ http://www.revistas.unifacs.br/index.php/redu/article/viewFile/341o/2444>. Acesso em: io Abr.2018. 
COSTA, Márcia. Lei do Georreferenciamento: o que é e para que serve? MK Avaliações Imobiliárias. 2018. Disponível em: 〈http://mkavaliacoesimobiliarias.com.br/lei-dogeorreferenciamento-o-que-e-e-para-que-serve/>. Acesso em: 24 Ag.2018.

FOLLE, Francis Perondi. O georreferenciamento de imóvel rural e o registro de imóveis. Pontifícia Universidade Católica do Rio Grande do Sul. 2008. Disponível em:<http://www3.pucrs.br/pucrs/files/uni/poa/direito/graduacao/tcc/tcc2/trabalhos2oo 8_2/francis_perondi.pdf >. Acesso em: 15. Out.2018.

INCRA. Instituto Nacional da Reforma Agrária. Sistema de Gestão Fundiária - Sigef. Brasília: INCRA, 2oI4.

JÚNIOR, Osvaldo Pessoa. Modelo causal dos primórdios da ciência do magnetismo. scientiæ zudia, São Paulo, v. 8, n. 2, p. 195-2112, 2010. Disponível em:<http://www.scielo.br/pdf/ss/v8n2/ao2v8n2.pdf >. Acesso em: 28 Ag.2018.

OLIVEIRA JÚNIOR, Gervásio Alves de. Aspectos Legais do Georreferenciamento. In: $20^{\circ}$ Encontro regional dos oficiais de registro de imóveis, 2005, Londrina. Disponível em: $\langle$ http://www.irib.org.br/notas_noti/boletimeli758.asp〉 Acesso em: 24 Set.2018.

OLIVEIRA, Ana Flávia de. Análise do processo documental de georreferenciamento após encaminhamento do processo ao cartório de registro de imóveis. Jan. 2017. Disponível em:<https://mundogeo.com/blog/2017/or/12/artigo-analise-do-processo-documental-degeorreferenciamento-apos-encaminhamento-do-processo-ao-cartorio-de-registro-deimoveis/>.Acesso em: o8 Agos.2018.

PALHARES. Marcos. Documentação cartorial uma peça técnica do georreferenciamento. Trabalho de Conclusão do Curso de Engenharia de Agrimensura. Faculdade de Engenharia de Minas Gerais. Belo horizonte. 2009. 
ROQUE, Cassiano Garcia. Georreferenciamento. Revista de Ciências Agro-Ambientais, Alta $\begin{array}{lllll}\text { Floresta, } & \text { v.4, } & \text { n.I, } & \text { p.87-I02, } & \text { Disponível }\end{array}$ em:〈http://www.unemat.br/revistas/rcaa/docs/vol4/ro_artigo_v4_.pdf 〉. Acesso em: 30 Abr.2018.

VIEIRA, Francisco Pedro. Importância do Georreferenciamento. Artigo (trabalho de conclusão de curso) que será apresentado ao curso de Pós-Graduação em Georreferenciamento, da Faculdade de Rolim de Moura - Farol em Cacoal/RO, 2007. 